\title{
A Study on Modifiers in the English Language
}

\author{
Qingsong Gu \\ Shanghai University of Engineering Science, Shanghai, China
}

\begin{abstract}
Over the past few decades, due to the development of applied linguistics, many systematic and theoretical achievements have emerged in the field of English language structure. However, in most grammatical monographs, the reference to Modifier is very general and it lacks a complete and precise definition. In this paper, for the first time, the author studies Modifier as a grammatical unit, and systematically explores it in terms of definition, classification, position and research purpose, so as to understand and explain some other phenomena of linguistic structure in English from a new perspective.
\end{abstract}

Index Terms-modifiers, definition, classification

\section{INTRODUCTION}

Over the past few decades, due to the development of applied linguistics, many systematic and theoretical achievements have emerged in the field of English language structure. However, in most grammatical monographs, the reference to Modifier (Mer or M) is very general and it lacks a complete and precise definition.

In the past, the studies on modifiers in English were confined to attributives that modify a noun phrase in the form of words, phrases or clauses. According to Liu Yingde, attributives are grammatical units before or after a noun or pronoun phrase that take the functions of modification, limitation or further explanation (Liu, 2002). By "attributive modifiers", Yang Qing means grammatical units modifying a central word in terms of characteristic, shape, scope or category, which include noun phrases, adjective phrases, participles and clauses (Yang, 1994). Li Farong and Ma Bingyu claim that as a modifier of a noun phrase, both relative clauses and other modifiers are similar in that they are closely connected with each other, the former being regarded as the deep structure and the latter the derivation of the former ( $\mathrm{Li}$, F. \& Ma, B., 1994). Some studies on modifiers in English were conducted from the angle of language style or language function. Yue Guixiang mentions that adverbial modifiers in scientific English are mostly adverbs ending with "ly" and seldom used in scientific English are adverbs for description or lyric (Yue, 2002). Adverbial modifiers can be classified into adjuncts, disjuncts and conjuncts in terms of function. Adjuncts typically modify verbs and disjuncts convey a comment on the content of the clause to which they are peripherally attached; conjuncts, on the other hand, are logical adhesives, functioning to connect a new sentence with the context.

It is true that Modifier has been discussed in various forms in many famous English grammars. For example, "modifier" and "modification" are mentioned many times in The Comprehensive Grammar of the English Language (CGE), written by Randolph Quirk, et al. in 1985. And in Contemporary English Grammar (CEG) written by Liu Shitong in 1997, modification is an equivalent to modifier. Also in 1997 A New English Grammar (NEG) chiefly edited by Zhang Zhenbang has a detailed discussion on modification of noun phrases. Unfortunately, no grammar gives a logical and definite definition of modifier. In CGE and CEG there are many examples demonstrating the modifying characteristic of some grammatical units, but no definition of modifier. In NEG no definition of modifier is given and, even worse, Chapter 40 in NEG confusingly emphasizes the difference between modifier and adverbial, neglecting the modifying function of adverbials.

In actual fact, the research of modifiers in the English language is of considerable value. In this paper, for the first time, the author studies Modifier as a grammatical unit, and systematically explores it in terms of definition, classification, position and research purpose, so as to understand and explain some other phenomena of linguistic structure in English from a new perspective.

\section{DEFINITION}

MODIFIER is discussed in various forms in many famous English grammars, in which the study of modification is restricted only within the range of words or phrases, but none of which gives a logical and complete definition of it. In my eyes, MODIFIER can be discussed as an independent structure in the English language. To be exact, a modifier (Mer) is a grammatical unit which limits or extends the meaning of another grammatical unit while a modifiee (Mee) is a grammatical unit whose meaning is limited or extended by another grammatical unit (Gu, 2003).

\section{ClassificATION}

Modifiers can be classified in terms of form, modifiee or function.

A. Classification in Terms of Form 
WORD, PHRASE, CLAUSE and SENTENCE are basic grammatical units in the English language, so modifiers can be classified as: Word Modifier (Mw), Phrase Modifier (Mp), Clause Modifier (Mc) and Sentence Modifier (Ms).

1) Word Modifier (Mw)

1. The enemy's attempt at a surprise $(\mathrm{Mw})$ attack (Mee) failed.

2. Only (Mw) in this way (Mee) can we accomplish our goals.

3. He was fired simply $(\mathrm{Mw})$ because he'd made too many private calls in the office (Mee).

4. Luckily $(\mathrm{Mw})$, I had just bought a new ribbon for my typewriter so I typed my application more satisfactorily (Mee).

2) Phrase Modifier (Mp)

1. Professor Wang (Mee), a famous computer expert from America (Mp), is going to visit our institute.

2. The girl made up (Mee) her face with great care (Mp) for her date.

3. In my opinion (Mp), most people like travelling by train better than by airplane (Mee).

4. Interestingly enough (Mp), she phoned me just as I was going to phone her (Mee).

3) Clause Modifier (Mc)

1. The news (Mee) that he failed in the exam (Mc)greatly surprised me.

2. I had no sooner (Mee) finished my work than she called me (Mc)

3. I turned to him (Mee) whenever I had difficulties (Mc).

4. As we know (Mc), the trend of peace is irresistible although wars are still going on in some areas (Mee).

4) Sentence Modifier (Ms)

1. The party is so (Mee) important that we all should attend it however busy we are (Ms).

2. The city looks no more (Mee) beautiful than I saw 10 years ago when I lived there (Ms).

3. She takes notes very carefully in class (Mee) in order that she can use them when she reviews her lessons after class $(\mathrm{Ms})$.

4. The teacher, young as he is, is very strict with us (Mee) possibly because he wants us to make rapid progress in English so that we can pass CET-4 next term (Ms).

It's worth mentioning that in a complex sentence the main clause is always modified by the subordinate clause introduced by a subordinator; in other words, it is the combination of a subordinator and the subordinate clause that makes up a modifier to limit or extend the meaning of the main clause. For example:

1. The girl (Mee) who is from England (Mc) can speak good Chinese. (who)

2. He set off again (Mee) although I attempted to dissuade him (Mc). (although)

3. I'm concerned about the question (Mee) how much the profit will decrease if more workers are employed (Ms). (how much)

4. He uses simple language (Mee) so that his foreign customer might understand him when no interpreters are available $(\mathrm{Ms})$. (so that)

\section{B. Classification in Terms of Modifiee}

As can be seen from the above examples, a modifiee can be not only a word or a phrase, but also a clause or a sentence. Therefore, modifier can be classified in terms of its modifiee as: Word-targeted Modifier (Mwt) and Clause-targeted Modifier (Mct). This classification eliminates the thought that what is modified is a word or a phrase rather than a clause or a sentence, thus considerably enlarging the range of modifiees and remarkably extending the function of modifiers.

\section{Classification in Terms of Function}

Modifiers, including all kinds of Attributive, Complement and Adverbial, are a large collection of grammatical units that bear various forms and have great functions. In terms of its functions, modifiers can be classified as: Attributive Modifier, Complement Modifier and Adverbial Modifier. Attributive Modifier can be further classified as: Pre-attributive Modifier and Post-attributive Modifier. Complement Modifier can also be further classified as: Subject Complement Modifier (Mcs) and Object Complement Modifier (Mco).

As a matter of fact, to classify modifiers is not the ultimate target, but a means of elaborate analysis and detailed research in this field. The further we classify, the more functions of modifiers we may know.

\section{POSITION}

\section{A. Position of Pre-attributive Modifier}

$\underline{\underline{a}} \underline{\underline{\text { distant }}} \underline{\underline{\text { small }}} \underline{\underline{\text { round }}}$ Pre-allow French wood $\underline{\underline{\text { reading }}} \frac{\text { room }}{\text { Mee }}$

The position of pre-attributive modifiers is relatively fixed and complies with the general rule shown in the table below. 


\begin{tabular}{|c|c|c|}
\hline \multirow{4}{*}{$\begin{array}{c}* \\
\text { Position of } \\
\text { Pre-attributive } \\
\text { Modifiers }\end{array}$} & Determiner & a \\
\cline { 2 - 3 } & Description & distant \\
\cline { 2 - 3 } & Size / Age / Shape & small round \\
\cline { 2 - 3 } & Color & yellow \\
\cline { 2 - 3 } & Origin & French \\
\cline { 2 - 3 } & Material & wood \\
\cline { 2 - 3 } & Type / Use & reading \\
\hline Modifiee & Central Noun & room \\
\hline
\end{tabular}

\section{B. Position of Complement Modifier}

The position of complement modifiers is also relatively fixed, but quite variable.

1. We have elected him (Mee) head of the institute $(\mathrm{Mco} / \mathrm{Co}$ ) last week.

2. $\underline{\mathrm{He}}$ (Mee) has been elected head of the institute (Mcs/Cs) last week.

\section{Position of Adverbial Modifier}

The position of adverbial modifiers is most variable and the changes of position may cause differences in meaning. Here are two examples.

1. Positions of "only"

Only (Mer) John saw the rabbit in the forest in spring. (No one else saw the rabbit.)

John only (Mer) saw the rabbit in the forest in spring. (John, possibly, didn't shoot it.)

John saw only (Mer)the rabbit in the forest in spring. (Not other animals.)

John saw the rabbit only (Mer) in the forest in spring. (Not in other places.)

John saw the rabbit in the forest only (Mer) in spring. (Not in other seasons.)

2. Positions of "surprisingly"

Population has surprisingly (Mer) increased. (Population has greatly increased.)

Surprisingly (Mer) population has increased. (The fact is a surprise.)

\section{RESEARCH PURPOSE}

In the late 1950's the American linguist N. Chomsky proposed the distinction between competence and performance, the former referring to the ideal user's knowledge of the rules of his language and the latter to the actual realization of this knowledge in linguistic communication. Linguistic research contributes not only to competence but also to performance. Similarly, the study of modifiers helps us to better understand certain complex grammatical phenomena in English so as to make good use of modifiers in practical linguistic communication.

\section{A. To Simplify Complex Grammatical Concepts}

The introduction of modifier simplifies some complex grammatical concepts in the English language. For example, all attributives can be generally regarded as modifiers simply because every attributive bears the function of modification.

$\underline{\underline{\text { such }}} \underline{\underline{\text { a beautiful long }}} \underline{\underline{\underline{\text { new }}}} \underline{\underline{\text { red }}} \underline{\underline{\text { Shanghai }}} \underline{\underline{100 \%}} \underline{\underline{\text { cotton women }}} \quad \underline{\underline{\text { dress }}} \quad \underline{\underline{\text { on sale }}}$ in the shop

Pre-attributive Mers $=\quad \overline{\text { Mee }} \quad \underline{\overline{\text { Post-attributive Mers }}}$

In addition, because complements also have the function of modification, all attributives, all complements and all adverbials can be thought of as modifiers, so the five basic elements of a clause (SVOCA) can be simplified to four (SVOM). Since M is an optional element in a clause, the necessary elements a clause has can be further simplified to three (SVO) or even two (SV). That's why SV is often used to refer to a simple sentence in grammatical analysis.

- SV. (simple sentence)

- SV and SV. (compound sentence)

- SV because SV. (complex sentence)

More importantly, the introduction of modifier makes it more understandable why subordinate clauses are classified as Noun Clause, Adjective Clause and Adverb Clause, because all the three subordinate clauses, together with their respective subordinators, have the function of modification. Appositive Clause is easily thought of as Attributive Clause simply because they both have the function of modification. Virtually, an Appositive Clause is a Noun Clause and an Attributive Clause is an Adjective Clause.

1. The news (Mee) that was spreading across the city (Mer) proved to be incorrect.

2. The news (Mee) that he had resigned his position (Mer)proved to be incorrect.

Most interestingly, all the three subordinate clauses can be referred to as one part of a phrase or one part of a main clause, which modifies the key word of the phrase or the main clause; therefore, all complex sentences can be reasonably simplified to simple sentences. This can be demonstrated in the changes from the following complex sentences:

1. The girl (Mee) who is from England (Mc) can speak good Chinese.

2. He set off again (Mee) although I attempted to dissuade him (Mc).

3. I'm concerned about the question (Mee) how much the profit will decrease if more workers are employed (Ms). 
4. He uses simple language (Mee) so that his foreign customer might understand him when no interpreters are available $(\mathrm{Ms})$.

respectively to the following simple sentences:

1. The girl (Mee) from England (Mp) can speak good Chinese.

2. He set off again (Mee) in spite of my attempt to dissuade him (Mp).

3. I'm concerned about the question (Mee) on the profit decrease as a result of additional employment (Mp).

4. He uses simple language (Mee) so as to let his foreign customer understand him with no interpreters available (Mp).

\section{B. To Explain Complicated Grammatical Structures}

By means of modifier some difficult structures in English can be better understood.

1. a great many (Mer) women workers (Mee)

2. a great many (Mee) of the women workers (Mer)

3. The cup is full (Mee) of water (Mer).

4. My father was rather disappointed (Mee) with my work (Mer).

5. I'm sure (Mee) that they will arrive on time (Mer).

6. I'm sure (Mee) of the fact that they will arrive on time (Mer).

7. I'm glad (Mee) that they've accomplished their goals (Mer).

8. I'm glad (Mee) because of the fact that they've accomplished their goals (Mer).

9. He realized that he came too much (Mer) early (Mee).

10. He realized that he came too (Mer) much (Mee) early.

11. He realized that he came (Mee) too much early (Mer).

12. Their thoughts are too (Mee) profound to be expressed clearly (Mer).

13. The questions are more (Mee) difficult than I've expected (Mer).

14. A whale is no more (Mee) a fish than a horse is (Mer).

15. Should they at least (Mer) conceal the truth until after the family vacation (Mee)?

16. Certainly I don't (Mer) teach because teaching is easy for me (Mee).

17. Until such (Mee) time as mankind has the sense to lower its population to the point where the planet can provide a comfortable support for all (Mer), people will have to accept more "unnatural food".

\section{To Obtain More Information when Reading}

In reading, one can obtain more information by studying and analyzing modifiers. A psychologist thinks of Complete Concept as the standard of a sentence while a grammarian regards SV as the standard of a sentence. A word and a phrase often convey simple concepts while a clause and a sentence convey comparatively complicated concepts. In reading, modifier serves as a bridge to form as many concepts as possible in order to obtain as much information as possible. For instance, we can, from the sentence:

I often drive to Pudong early in the morning, as do many businessmen who live in downtown Shanghai.

firstly obtain a general concept:

I often drive to Pudong.

and then, with the help of modifiers, get more concepts such as:

1. Many businessmen often drive to Pudong.

2. Many businessmen live in downtown Shanghai.

3. It is early in the morning that I, as well as many businessmen, often drive to Pudong.

So, we may call this method of reading "Modifier Reading" or "SV Reading".

\section{To Apply Modification-guided Strategies in En-Cn Translation}

The essence of modification is semantic limitation or extension, so the translation of modifiers from English to Chinese should first take meaning conveyance into consideration. But, due to the difference between English and Chinese, the form and style of modifiers in English should also be paid enough attention to in translation. Since modifiers in this paper are mainly analyzed on a linguistic level, culture is excluded from the discussion on translating strategies.

On the basis of studies on modifiers in the English language, the author puts forward in this chapter three strategies for translating modifiers from English to Chinese from the angles of form, meaning and style - conveying meaning through conceptualization and contextualization; restructuring form through lexical conversion and order rearrangement; and reproducing style through naturalization.

1) Conveying Meaning Through Conceptualization and Contextualization

Meaning is something conveyed or signified. The process of translation is using another language to convey the original meaning, the original meaning maintained while the language changed. Although there are different views on translation criterion, being faithful to the original meaning (faithfulness) is given priority to (Fang, 2004). In translation, conceptualization is an effective way to have an adequate understanding of the original. In general sense, conceptualization means the process of forming a concept in mind. For example, in the sentence: 
The large house in which the businessman lived has been sold to a farmer who owns lots of money.

The reader may get simple concepts on a lexical level such as "large", "house", "businessman", "live", "sell", "own", "money". These lexical concepts are isolated from each other in meaning. According to grammarians, the standard of a sentence is whether or not it contains a subject and a verb; in the eyes of psychologists, the standard of a sentence is whether or not it conveys a complete concept. From the above sentence the reader can get some complete concepts through conceptualization on a syntactical level:

The house has been sold.

A farmer bought the house.

The house is very big.

The businessman lived in the house.

The farmer is very rich.

Modification, always related to semantic meaning, is frequent and flexible in English, so the translation of modifiers in English largely decides the quality of the whole translation. Conceptualization helps a lot in translating modifiers in English. The translation of modifiers considerably depends on the extent to which the translator conceptualizes them. For example, in the following assumed translations of the above sentence, modification is conceptualized in different degrees. In Translation 1 modification is fully conceptualized while in Translation 5 modification is zero-conceptualized.

Original: The large house in which the businessman lived has been sold to a farmer who owns lots of money.

Translation 1: 该商人曾经住过的大房子已被卖给了一个有钱的农民。

Translation 2: 该商人曾经住过的大房子已被卖给了一个农民。

Translation 3: 大房子已被卖给了一个有钱的农民。

Translation 4: 大房子已被卖给了一个农民。

Translation 5: 房子已被卖给了一个农民。

Another effective way of guaranteeing meaning conveyance in translating modifiers is contextualization, which refers to translating some modifiers as connective devices in order to reflect the coherence of the original text. For example,

Original: Unfortunately (Mer), most students in rural areas have no access to electronic books.

Translation: 不幸的是, 农村里多数学生无法得到电子图书。

"unfortunately" in the original is a content-disjunct which modifies the clause attached. But, if used between sentences, it may be translated as a style-disjunct to achieve contextual coherence, as demonstrated below.

Original: Electronic books are very common in cities. Unfortunately (Mer), most students in rural areas have no access to electronic books.

Translation: 电子图书在城市里很普及。但是, 农村里多数学生无法得到电子图书。

2) Restructuring Form Through Structural Conversion and Order Rearrangement

In broad sense, as the materialistic manifestation of language meaning, language form includes buildings of words and phrases, sentence patterns, text arrangements, rhetoric devices as well as phonemic effects such as intonation, rhythm and rhyme. As we know, translation is neither word-to-word translation nor sentence-to-sentence translation. Form may be restructured in translation under the prerequisite of successful conveyance of meaning. In the practice of translating, modifiers in English may be converted from one part of speech to another, from one kind of clause to another and may be rearranged to achieve more adequate conveyance of meaning.

3) Reproducing Style Through Naturalization

Naturalization refers to the translation strategy through which a fluent style is achieved to minimize the strangeness of the foreign text for target language readers, while foreignization designates the type of translation in which a target text deliberately breaks target conventions by retaining something of the foreignness of the original. In most cases, naturalization and foreignization is a pair of concepts which are frequently used to discuss cultural transplanting. But, from the angle of pure linguistics, naturalization includes minimizing "the strangeness of the foreign text for target language readers" in grammatical rules, semantic meaning, and stylistic characteristics. The task of translation not only gives priority to conveying semantic meaning but also involves reproducing style in the receptor language. In translating modifiers in English, naturalization is preferred primarily because linguistic forms of English and Chinese are quite different even though they are of the same style. For example, in legal English some modifiers should be translated according to the style of legal Chinese, otherwise the translation wouldn't be idiomatic. Here is an example.

Original: We hereby (Mer) certify that...

Translation 1: 我们在这里证明......

Translation 2: 我们在此证明......

Translation 3: 兹证明...... 
Among the three translations, Translation 3 is the most idiomatic. Another good example is:

Original: This Policy of insurance witnesses that The People's Insurance Company of China (hereafter called "The Company") (Mer), at the request of NANTONG FAR-EAST TRADING CO. (hereafter called the "Insured") (Mer), and in consideration of the agreed premium paying to the Company by the Insured, undertakes to insure the under-mentioned goods in transportation subject to the conditions of this Policy as per the clause printed overleaf and other special clause attached hereon.

Translation 1: 中国人民保险公司（下面叫做本公司）根据南通远东贸易公司（下面叫做被保险人）的要求， 由被保险人向本公司缴付约定的保险费, 按照本保险单承保险别和背面所载条款与下列特款承保下述货物运输 保险, 特立本保险单。

Translation 2: 中国人民保险公司（以下简称本公司）根据南通远东贸易公司（以下简称被保险人）的要求， 由被保险人向本公司缴付约定的保险费, 按照本保险单承保险别和背面所载条款与下列特款承保下述货物运输 保险，特立本保险单。

Comparatively, the underlined modifiers in Translation 1 are not translated according to the style of legal Chinese while Translation 2 is more idiomatic.

\section{SUMMARIZATION}

The modifier in the English language is a highly generalized linguistic structure (or grammatical unit) abstracted from the English linguistic system, which complements and develops the English grammatical system. Its linguistic functions are mainly embodied in the limitation or extension of the meaning of the modifier. In verbal communication activities, we can recognize this linguistic structure phenomenon by means of transforming and generating concepts, make full use of its linguistic functions, and obtain as much information as possible, so as to achieve the goal of improving speech ability.

\section{REFERENCES}

[1] Fang, M. (2004). A Dictionary of Translation Studies. Shanghai: Shanghai Foreign Language Education Press.

[2] Gu, Q. (2003). Courses in English Writing. Suzhou: Soochow University Press.

[3] Gu, Q. (2003). Modifiers in the English Language. Journal of Nantong Institute of Technology (Social Science), 6, 68-71.

[4] Li, F. \& Ma, B. (1994). The Relationship Between Relation Clauses and Noun Modifiers. Shanghai Journal of Traslators for Science and Technology, 3, 21-23.

[5] Li, J. (1998). A Modern English Grammar. Beijing: Foreign Language Teaching and Research Press.

[6] Liu, S. (1997). Contemporary English Grammar. Beijing: Xueyuan Press.

[7] Liu, Y. (2002). A Discussion about Modifiers of Nouns. Journal of Chongqing Jiaotong University (Social Sciences Edition), 3 , 72-74.

[8] Quirk, R., Greenbaum, S., Leech, G. \& Svartvik, J. (1985). A Comprehensive Grammar of the English Language. New York: Longman Group Limited.

[9] Wang, D. (1997). An Introduction of Linguistics. Shanghai: Shanghai Foreign Language Education Press.

[10] Yang, Q. (1994). On Variations of Attributive Modifiers. Journal of Binzhou Teachers College, 3, 79-82.

[11] Yue, G. (2002). On the Adverbial Modifiers in the scientific and Fechnical English Essays. Journal of Weifang University, 6 , $78-80$.

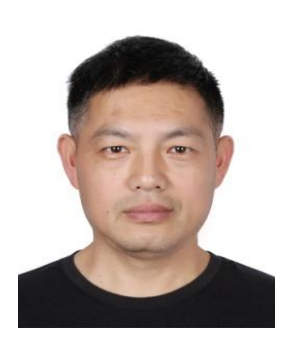

Qingsong Gu, associate professor from School of Foreign Languages at Shanghai University of Engineering Science, earned an MA degree in English at Shanghai Maritime University and has been teaching English in China for more than 15 years. His research focuses on Teaching English as a Second or Foreign Language. 